\title{
Secondary Chorionic Villus
}

National Cancer Institute

\section{Source}

National Cancer Institute. Secondary Chorionic Villus. NCI Thesaurus. Code C34291.

The second stage of chorionic villi development, which generally occurs during the third week of embryonic development, and is characterized by the appearance of a mesenchymal core within an expanding villus. 